\title{
Special issue of the 6th International Conference on Boiling Heat Transfer and to Prof. Dr.-Ing. Dieter Gorenflo on his 70th birthday
}

\author{
Andrea Luke
}

Published online: 17 March 2009

(C) Springer-Verlag 2009

Since the beginning of the 1990s of the last century the heat transfer community has made significant advances in experimental and theoretical understanding of the heat transfer with phase change. These activities coincided with the increasing interest in energy efficient systems. The current special issue is devoted to the 6th International Conference on Boiling Heat Transfer held in Spoleto (Italy) in 2006, which included more than 90 peer reviewed paper presentations from 20 countries. The conference offered a truly international scientific exchange of research in boiling heat transfer. The formal and informal sessions at the conference provided various opportunities for discussing individual papers and general issues and future research collaborations facing the transport processes. The technical program included presentations on the following topics: Nucleate and flow boiling, spray cooling, critical heat flux, falling film evaporation and enhancement of boiling heat transfer.
The papers published in this special issue were preselected by the conference chair and his co-chairs and were peer reviewed for publication in Heat and Mass Transfer. These papers reflect a spectrum of topics of current interest in boiling transfer in a wide range. Additionally, the special issue is dedicated to Prof. Dr.-Ing. Dieter Gorenflo on the occasion of his 70th birthday, an active attendee of all six editions of this conference series, to recognize his outstanding contributions of the science of boiling heat transfer.

I would like to acknowledge gratefully the Laudatio provided by Prof. David Kenning, and the overview of the conference by the Conference chair, Prof. Gian Piero Celata. I want to express special thanks to the authors for their contributions to this special issue, and the reviewers of the manuscripts for their invaluable input, responsiveness and for making the publication of this special issue possible. I deeply appreciate the contribution of the organizers of the Conference, Prof. G. P. Celata and his team.

\footnotetext{
A. Luke $(\bowtie)$

Institut für Thermodynamik, University of Hannover,

Callinstrasse 36, 30167 Hannover, Germany

e-mail: luke@ift.uni-hannover.de
} 